\title{
MECHANICAL BEHAVIOR OF BANANA REINFORCED EPOXY COMPOSITE BY FINITE ELEMENT METHOD
}

DOI : 10.36909/jer.ICIPPSD.15515

Upendra Sharan Gupta*, Sudhir Tiwari**, Rajeev Namdeo*, Siddhartha Chaturvedi*

*Shri Vaishnav Vidyapeeth Vishwavidyalaya, Indore

**Shri Govindram Sakseria Institute of Technology and sciences, Indore

*Email: upendra sharan@yahoo.co.in ; Corresponding Author.

\begin{abstract}
In the recent years, there is a shift in interest of engineers and researchers to natural fibres from synthetic fibres. Natural fibres have high strength, are light weight and are also inexpensive than the traditional synthetic fibres. In addition, the fibres obtained naturally are biodegradability and eco-friendly in nature. Banana fibre is a derived product by cultivation of banana fruit and thus plentiful in environment. Banana fibre is classified among the strongest naturally obtained fibre and therefore when reinforced with other few binding resins can be utilized for different applications. Epoxy resin are suitable matrix for composite creation since they have outstanding binding characteristics. The (FEA) Finite Element Analysis of epoxy-banana composite shows that the maximum value of impact, flexural and tensile load that the composite can bear is $1000 \mathrm{~N}, 900 \mathrm{~N}$ and $2100 \mathrm{~N}$ respectively. According to this investigation it can be concluded that because of their outstanding load bearing characteristics epoxy-banana composite can be utilized for several medium load industrial uses to high load industrial uses. It is observed that the composite with least volume percent of epoxy has better mechanical strength and can bear higher deformation under higher load for tensile and flexural tests and for the impact strength results, the increase in fibre \% results in lower impact strength. Also, the increase in higher vol. \% of epoxy results in lower stiffness and higher deflection in the specimens, except for the specimen with $40 \%$ vol. of epoxy which obtained the most optimal results.
\end{abstract} Keywords: Banana Fibre reinforced epoxy composite, Finite Element Analysis, Natural Fibre.

\section{INTRODUCTION}

Banana fibre, hemp, wood, abaca, coconut, kenaf, sisal, jute, cotton, flax, wheat straw, bamboo, etc. are plant derived fibres and therefore known as natural fibres. When the reinforcement of natural fibres is done with plastic binder, they form a hard-composite 
substance. Synthetic fibres advancement was considered as a better substitute to the traditional forms of materials like aluminum and steel. As compared to aluminum and steel, the synthetic fibres are light in weight and stronger respectively. As compared to steel the natural fibres are less strong and resembles the strength of steel upto $70 \%$ and on comparing natural fibres to synthetic fibre alternatives, natural fibres are lighter than the synthetic fibre alternatives. Furthermore, natural fibre is very much cost-effective compared with the synthetic fibres as they are plentiful in nature. Because of these features there is a shift in attention of engineers and researchers.

On the treatment of bark of banana tree banana fibre can be obtained and it is a kind of bast fibre. For cultivation of new crop, it becomes essential to cut down banana trees once the banana fruit is cultivated in a season, because now it is useless and is nothing more than a bio waste. The cut down banana trees are transformed to raw banana fibre by drying and processing it at minimal cost. Banana fibre has several advantages like high fibre strength and low density since it is a lingo-cellulosic fibre. Furthermore, being produced from biowaste and being plentiful in nature it is cheaper than other forms of artificial fibres. Unlike the synthetic fibres, these fibres are environment friendly and biodegradable.

Reinforcement of banana fibre with plastic resin develops a hard-composite material, which been found to have good mechanical properties. Banana fibre becomes hard material when reinforced by resin binder which can be easily molded into a rigid shape (Ramesh.,2017). It has been found that the several properties and strengths of composite are extremely reliant on either volume fraction or weight fraction of the added resin ( Prasad.,2014). Also, it has been seen that the properties depend on factors like anisotropy, interphase properties and porosity (Rajesh.,2016).

Materials comprising of two or more than two chemically discrete components that have a dissimilar interface that separates them are hybrids (Gupta.,2020). A material consisting of one or more than one discontinuous phase set in an incessant phase is known as a composite. Reinforcement is the intermittent phase, as it is stronger and harder in comparison to the continuous phase. The continuous phase is known as matrix. Both of these phases when combined and adjoined together are called as the composite.( Balasubramanian.,2019) A better set of mechanical characteristics can be gained by blending two or more fibre's hybrids as compares to non-hybrid composites. Synergistic effects among both the fibres make it harder to predict mechanical properties.

The process of resolving engineering problems using FEA software by dividing 3dimensional model of a sample into very small elements of finite number is known as Finite Element Analysis. Depending on the surface construction of the specimen several 
mesh can be selected. The calculation of the result of the analysis is done on the mesh nodes. It was found from the outcomes of the literatures that the mechanical behavior of natural fibre can be analyzed using FEA model when the fibres in actual composite are arranged symmetrically and regularly, because the results acquired from the experimental tests were close to the FEA model (José da Silva., 2012).

\section{LITERATURE SURVEY}

Vishnu Prasad et. al. (2014) performed Finite Element Analysis on hybrid polymer matrix reinforced with jute-banana. The composite specimen is prepared with varying CNSL\% from 5 - $40 \%$. With the help of modelling software 3-Dimensional model of specimen was created. Tensile test was performed both by FEA and experimentally on the specimen with dissimilar geometries. Plotting was done for specimen with variable composition between \% CNSL properties and the maximum load.

Ravi Tumkur Suryavanshi et. al. (2016) using Finite Element Analysis tried to find the stress intensity factor of hybrid polymer matrix composite reinforced by banana fibre. Hand lay-up method was used to fabricate the CNSL-Banana composite. The specimen dimensions are $96.5 \mathrm{~mm} \times 22 \mathrm{~mm} \times 5.5 \mathrm{~mm}$ and specimen were created according to ASTM D5045. 3-Dimensional model of specimen for finite element analysis was prepared by means of modelling software and the FEA software was used to simulate the test conditions. It was found that with the increase in amount of CNSL the fracture toughness of the composite decreases and optimum stress intensity factor was obtained for the sample with $5 \%$ CNSL.

Leandro José da Silva et. al. (2012) Analyzed natural fibre reinforced bio composites experimentally and numerically. Sisal and Banana composites were created accordingly and scanning electron microscopy and tensile test were conducted using it. Modelling software was used to create 2-dimensional and 3-dimensional model of the specimen and testing conditions were kept same for subjecting. Since the result of FEA were close to that of experimental analysis, conclusion was made that to estimate mechanical characterization of natural fibres FEM can be used when the fibre arrangement in actual composite is regular and symmetry.

P. Shashi Shankar et. al. (2013) assessed the mechanical characteristics of epoxy composite reinforced by banana. In order to examine, for specific test according to the ASTM standards the specimen of variable fibre volume fraction were created accordingly. Charpy impact, impact and tensile test were the tests to which specimen was subjected. 3-dimensional model of the specimen was created assuming the fibre 
orientation as unidirectional. Comparison of FEA and experimental result both were done respectively.

M. Rajesh et. al. (2016) investigated the outcomes of Finite Element Analysis of hybrid composite material reinforced Banana/Coir. Composition of epoxy composite reinforced by banana-coir, epoxy reinforced by banana and epoxy reinforced by coir was used to create model with dimensions $100 \times 100 \times 10$. FEA results and experimentally obtained results were associated and found close to each other. From FEA it was determined that by increasing fibre percentage it is possible to decrease stress concentration besides the small difference in FEM and experimental values is because some phenomenon like interphase properties, anistrophy and porosity were neglected.

T. Hariprasad et. al. (2017) using FEM and experimental techniques examined the characteristics of hybrid composite of banana coir. Hand lay-up method was utilized for the fabrication of the epoxy composites reinforced by coir and banana and were treated chemically further. The dimensions of the specimen were according to the dimensions of ASTM standards for flexural, impact and tensile tests and accordingly the specimen was constructed. To investigate finite element analysis, modelling software was used to construct the models of specimen and ANSYS 11.0 was used to simulate the tests results. It was noted that on alkali treatment of composite the flexural strength reduced while impact and tensile strengths of coir and banana fibres enhanced. Moreover, the experimental and the FEA results were close thus to forecast the mechanical behavior of composites of fibre, FEM can be used.

Shivanshu Dixit et. al. (2019) investigated characteristics of composites reinforced by fibre and performed (FEA) finite element analysis on them. Construction of the specimen was done using five dissimilar kinds of fibres and twenty-five dissimilar combinations of them were prepared. ANSYS- MECHANICAL ADPL software was used to design the specimen to test its mechanical characteristics. The mechanical characteristics were selected as linear isentropic, and the designed element was selected to be 3D 4shell 181. In perpendicular direction a point load of $200 \mathrm{KN}$ was applied on 17 nodes. The angles of orientation of fibre were taken as $-45,0,90$ and 45 . The thickness of the specimen was $0.2 \mathrm{~mm} /$ layer along with 5 such layers and the dimensions of specimen were $200 \mathrm{~mm} \mathrm{x}$ $20 \mathrm{~mm}$. The comparison of the composites was done according to the $\mathrm{x}, \mathrm{y}, \mathrm{z}$ components of rotation, $\mathrm{x}, \mathrm{y}$ direction stress and $\mathrm{x}, \mathrm{y}, \mathrm{z}$ direction deformations.

Mario D. Monẑon et. al. (2019) analysed and simulated the mechanical behavior of woven composite reinforced by banana fibres. The specimen was fabricated as per ISO standards for the relative tests. A 3D model of the specimen was constructed for 
simulation purposes. The results of the simulations were compared to the results of the experimental tests of the tests and that obtained by numerical model, and it was observed that all the models displayed negligible variance, hence all of the models can be considered accurate.

Manickram Ramesh et. al. (2017) analyzed the hybrid composite reinforced by carbonbanana fibres for its mechanical properties. Fabrication of the specimen was done with respect to the relative ASTM standards for tensile, impact water intake and flexural tests. ANSYS 15.0 was used for the FEA (Finite Element Analysis) of the specimen model. The FEA results and the experimental results were compared, and the general trends were observed. It was observed that the results of the experimental analysis and FEA displayed negligible variance and thus it was concluded that the mechanical behavioral characteristics can be determined by finite element method.

M. Ramesh et. al. (2018) utilized finite element analysis to determine the mechanical and morphological characteristics of hybrid composite reinforced by glass-flax. Hand layup method was used for the fabrication of the specimen. The specimens were prepared as per the respective ASTM standards for tensile, impact and flexural test. ANSYS 12.0 was used for the construction and finite element analysis of the specimen model. The experimental results were observed and the specimen with highest strength was determined. It was concluded that the FEA results were substantiated by experimental results and thus it was determined that the FEA model can be reliably considered.

Vishnu Prasad et. al. [14]utilized the Finite Element Method (FEM) to determine the mechanical behavior of jute fiber polymer matrix composite. hand lay-up method was used to fabricate the jute-CNSL composite. An INSTRON testing machine was used to conduct the tensile test on the specimen. ANSYS was used for the Finite Element Analysis of the specimen model. The curves for load vs \% CNSL characteristics of variable CNSL percentage in the composites and load vs deformation were plotted.

M. Ramesh et. al. (2019) utilized the finite element method to determine the mechanical characteristics of polymer composite reinforced by glass-kenaf fibre hybrid. Hand layup method was used in fabrication of the composite. The specimen was prepared according to the relative ASTM standard dimensions for tensile, impact and flexural tests. NX NASTRAN 9.0 software was used for the Finite Element Analysis of the specimen model. It was concluded that both the FEA and experimental test results were approximately similar. Hence it can be deduced that FEA model can be used to determine the mechanical properties of the specimen.

Adewale George Adeniyi et. al. (2019) analyzed the polystyrene composite reinforced 
by sisal fibres, utilizing a multi-scale finite element analysis. Injection molding machine that was hand operated, was used in the fabrication of the composite specimens of fibre percentages of $10 \%, 20 \%, 30 \%$ and $40 \%$ by weight. ABAQUS 6.14 was used for the Finite Element Analysis of the specimen model. 3D representation method was employed for the construction of the specimen model. Different curves for fibre loading vs longitudinal modulus, fibre loading vs poisson's ratio and fibre loading vs transverse modulus were plotted.

Siva Bhaskara Rao Devireddy et. al. (2012) investigated the change in elastic and thermal properties of unidirectional composites reinforced by fibers, due to representative volume element and fibre geometry. RVE model was employed on ANSYS to construct the specimen model. fibre loading vs longitudinal modulus, fibre loading vs poisson's ratio and fibre loading vs transverse and fibre loading vs in plane shear modulus were plotted and analyzed. Another curve was also plotted to determine the change in thermal conductivity due to volume fraction.

K. Balasubramanian et. al. (2020) employed finite element method and experimental testing to determine the mechanical characteristics of natural fibre-reinforced composites. Hand layup technique was used for the fabrication of the specimens. The specimens were prepared as per ASTM standards with dimensions for impact and tensile tests. ANSYS software was used for the FEA of the three-dimensional specimen models. The FEA and experimental analysis results were compared, and it was determined that both the models came out to be approximately similar. Hence, it was concluded that FEM can be used to determine the mechanical behavioral characteristics of the composite material.

\section{MATERIALS AND METHODOLOGY}

The orientation of the fibre is $0^{\circ}$ and the EBEBE (E-Epoxy, B-Banana) stacking was used for the creation of the composite model. Based on, total thickness x volume fraction / no. of layers (i.e., 3 layers of epoxy and 2 layers banana) each layer thickness is determined. PTC CREO 5.0 (India) was used to create five samples each of composition 50-50, 6040, 70-30, 80-20, 90-10 for each test specimen. The dimensions of the specimen used for tensile test were $145 \mathrm{~mm} \times 20 \mathrm{~mm} \times 4 \mathrm{~mm}$ and as reported by ASTM D638 the test was performed. The dimensions of the specimen used for flexural test were $60 \mathrm{~mm}$ x $10 \mathrm{~mm}$ x $4 \mathrm{~mm}$ and based on ASTM D790 the test was performed. ASTM D256 standards were used for the Izod Impact test and $63 \mathrm{~mm} \times 12.7 \mathrm{~mm} \times 3 \mathrm{~mm}$ were the dimensions of the specimen used. ANSYS Workbench 16.0 (India) was the FEA software used for analysis and the model was created using PTC CREO 5.0 (India). FEM was applied on the 
specimen in ANSYS Static Structural. The dimensions of sample on which the Brinell Hardness test was conducted are $20 \mathrm{~mm} \times 20 \mathrm{~mm}$ × $6 \mathrm{~mm}$. The maximum load used for tensile, impact and flexural test was $21412 \mathrm{~N}$ at $0.1 \mathrm{~V}_{\mathrm{f}}, 1192 \mathrm{~N}$ at $0.1 \mathrm{~V}_{\mathrm{f}}, 1534 \mathrm{~N}$ at $0.1 \mathrm{~V}_{\mathrm{f}}$ respectively. The Deflection and Stiffness Test of the composite specimen were performed as per ASTM D7264. The specimen of dimensions $153.6 \mathrm{~mm}$ x $13 \mathrm{~mm}$ x 4 $\mathrm{mm}$ was created with volume fraction of epoxy $0.1 \mathrm{~V}_{\mathrm{f}}, 0.2 \mathrm{~V}_{\mathrm{f},}, 0.3 \mathrm{~V}_{\mathrm{f},} 0.4 \mathrm{~V}_{\mathrm{f}}$ and $0.5 \mathrm{~V}_{\mathrm{f}}$ by composition were modelled on PTC CREO 5.0 (India) as a parallel layer composite with EBEBE stacking. A three-point loading configuration was used in the strain and deflection analysis.

During meshing the element size of the specimen model was kept at $2 \mathrm{~mm}$ for the (FEA) finite element analysis and the geometry of the elements of the specimen model were kept as tetrahedral. The total nodes and total elements were found to be 83149 and 4506 respectively with a transition ratio of 0.272 and growth rate of 1.2. The mesh was generated in Static Structural and to determine the independence of the mesh, a grid independence test was performed.

A graph for element size vs resultant stresses was plotted to determine the consistent element size of the mesh. It was observed that the element size of $1 \mathrm{~mm}$ and $2 \mathrm{~mm}$ provided the most optimum results and in this range the results of the FEA appeared to be constant. Hence, to save time and accurately determine the outcomes of the FEA, the mesh size of $2 \mathrm{~mm}$ was applied.

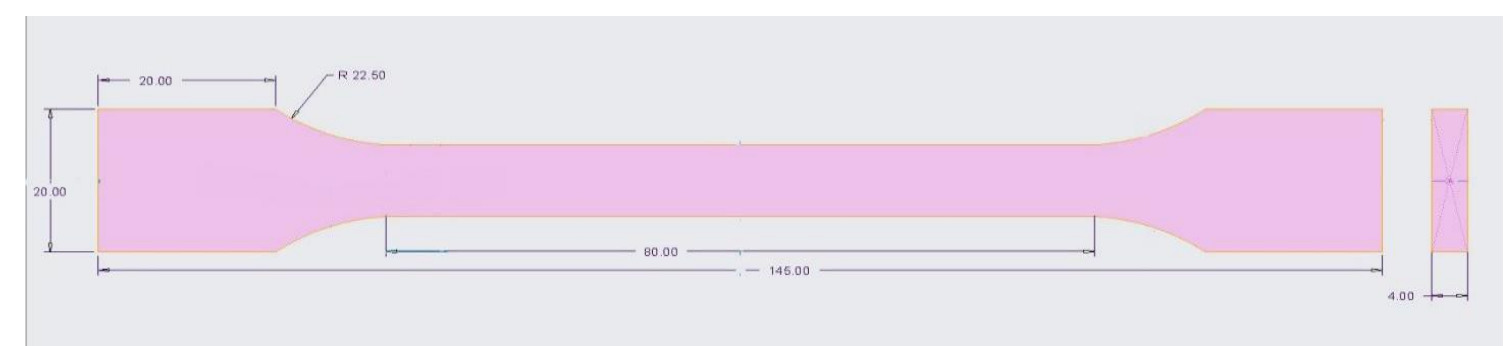

Figure 1 Specimen for Tensile Test 
Figure 2 Specimen for Impact Test

Figure 3 Specimen for Flexural Test

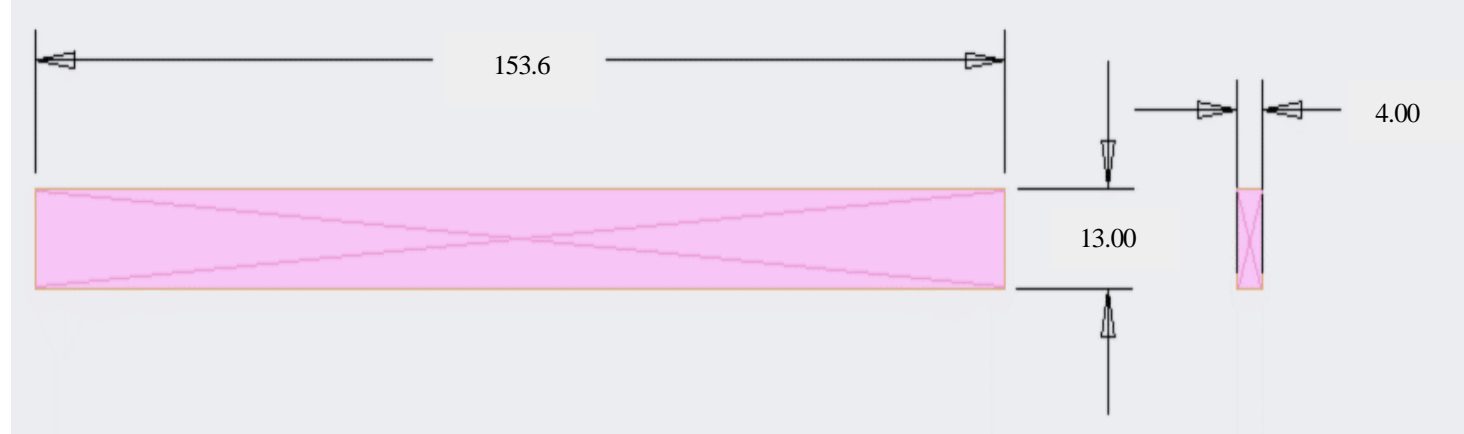

Figure 4 Specimen for Deflection Test

\section{THEORITICAL MODELLING}

\section{Failure Strength}

Parallel layer composite is developed to analyze the epoxy composite of banana. The strength properties of both, the epoxy and the fibre is very distinct. Using the rule of parallel mixture taking 54.6 $\mathrm{MPa}$ as epoxy strength and $750 \mathrm{MPa}$ as raw banana fibre strength, the overall strength for the (E-B-E-B-E) composite is calculated [18]. Based on this, the equation provides the tensile strength of the composite reinforced by fibre[19]. Where, $V(m)$ is volume fraction of matrix, $V(f)$ is volume fraction fibre, $T(m)$ is strength of matrix, $T(f)$ is strength of fibre and Tc is failure strength of composite.

$$
T c=\mathrm{T}(\mathrm{f}) \mathrm{V}(\mathrm{f})+\mathrm{T}(\mathrm{m}) \mathrm{V}(\mathrm{m})
$$

Table 1 Failure Strengths of various composites

\section{\begin{tabular}{l|l} 
Volume \% of composite (E: B) & Failure strength (MPa)
\end{tabular}}




\begin{tabular}{|c|c|}
\hline $10: 90$ & 679.88 \\
\hline $20: 80$ & 611.02 \\
\hline $30: 70$ & 540.98 \\
\hline $40: 60$ & 472.12 \\
\hline $50: 50$ & 401.89 \\
\hline
\end{tabular}

\section{Deflection and Stiffness:}

The Deflection of the specimen were calculated with respect to the strain at the outer layer of the composite specimen model. The strain generated was analyzed and the corresponding values were validated through the following equation:

$$
\epsilon=\frac{6 \delta \mathrm{h}}{\mathrm{L}^{2}}
$$

where:

$\delta=$ mid-span deflection, $\mathrm{mm}$,

$\epsilon=$ maximum strain at the outer surface, $\mathrm{mm} / \mathrm{mm}$,

$\mathrm{L}=$ support span, $\mathrm{mm}$ and

$\mathrm{h}=$ thickness of beam, $\mathrm{mm}$.

While the stiffness was calculated through the given relation between load and deflection, which is:

$$
\mathrm{K}=\frac{\mathrm{P}}{\delta}
$$

where:

$\mathrm{K}=$ Stiffness of the composite, $\mathrm{N} / \mathrm{mm}$,

$\mathrm{P}=$ Load applied on the mid-span of the body, $\mathrm{N}$ and

$\delta=$ mid-span deflection, $\mathrm{mm}$.

\section{RESULT AND DISCUSSION}

\section{Tensile Test}

The table below depicts the Tensile test results for various specimen ranging from $10 \%$ to $50 \%$ Epoxy by volume. In addition, the maximum load before its failure and the maximum deformation in tensile loading on various specimens were compared using a line graph. It was found that the specimen having $10 \%$ epoxy having maximum tensile strength. It was observed that the specimen with $10 \%$ epoxy showed a maximum deformation of $2.092 \mathrm{~mm}$ and the maximum bearable load of $21412 \mathrm{~N}$. Whereas, the specimen with $50 \%$ of epoxy by volume obtained the minimum deformation and minimum bearable load of $1.239 \mathrm{~mm}$ and $7779 \mathrm{~N}$ respectively. 


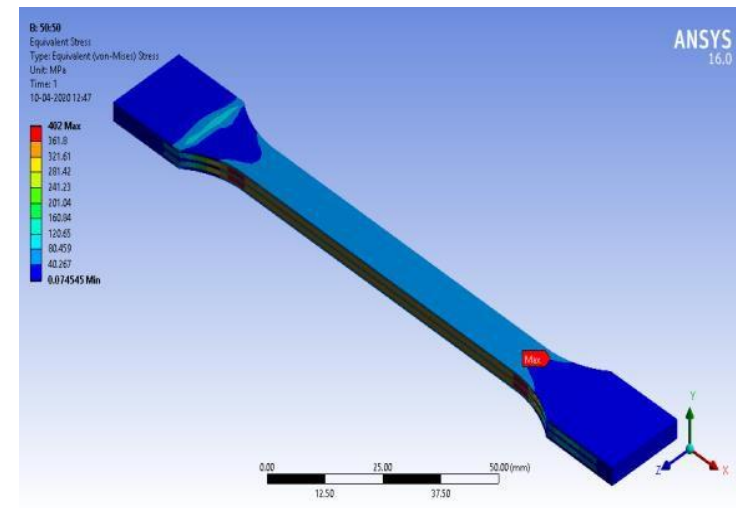

Figure 5 Maximum equivalent stress for Tensile test

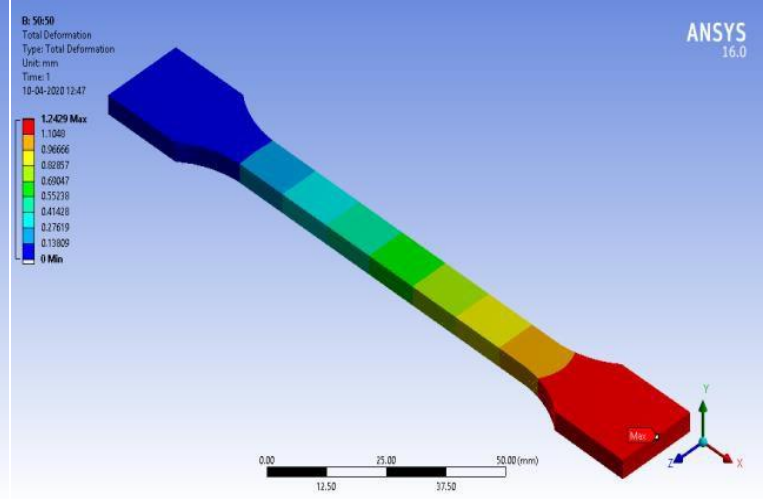

Figure 6 Deformation of tensile test

Table 2 Results of Tensile test

\begin{tabular}{|c|c|c|c|}
\hline $\begin{array}{c}\text { Volume \% of } \\
\text { Epoxy }\end{array}$ & Max. Load (N) & $\begin{array}{c}\text { Max. } \\
\text { Stress } \\
\text { (MPa) }\end{array}$ & $\begin{array}{c}\text { Max. } \\
\text { Deformation } \\
(\mathbf{m m})\end{array}$ \\
\hline 10 & 21412 & 681.01 & 2.092 \\
\hline 20 & 17305 & 610.84 & 1.895 \\
\hline 30 & 13703 & 539.89 & 1.669 \\
\hline 40 & 10501 & 470.95 & 1.436 \\
\hline 50 & 7779 & 398 & 1.239 \\
\hline
\end{tabular}

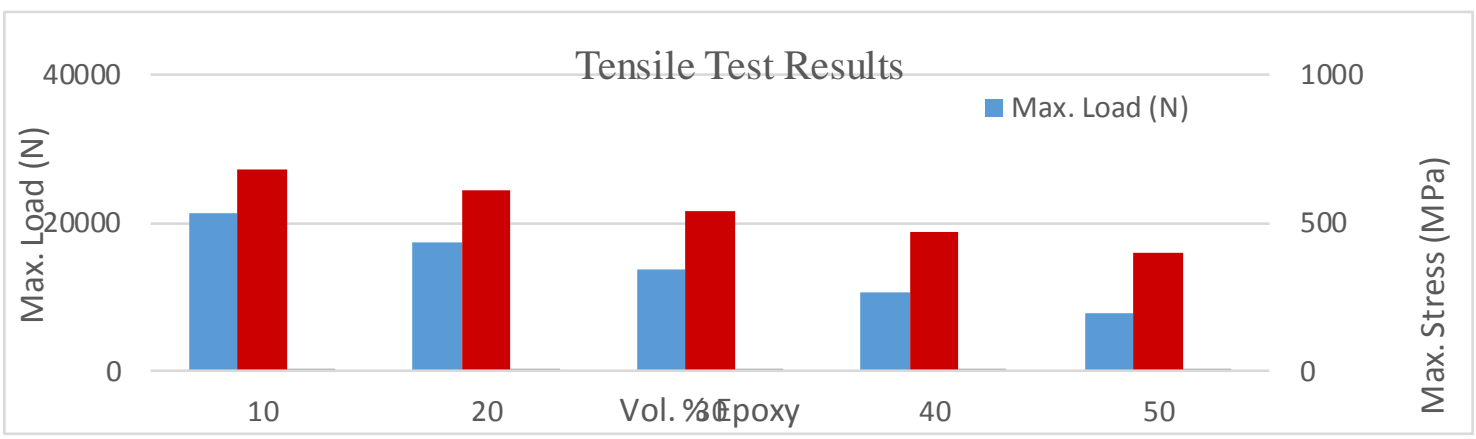

Graph 1 Max load and max. stress vs vol.\% epoxy for tensile test

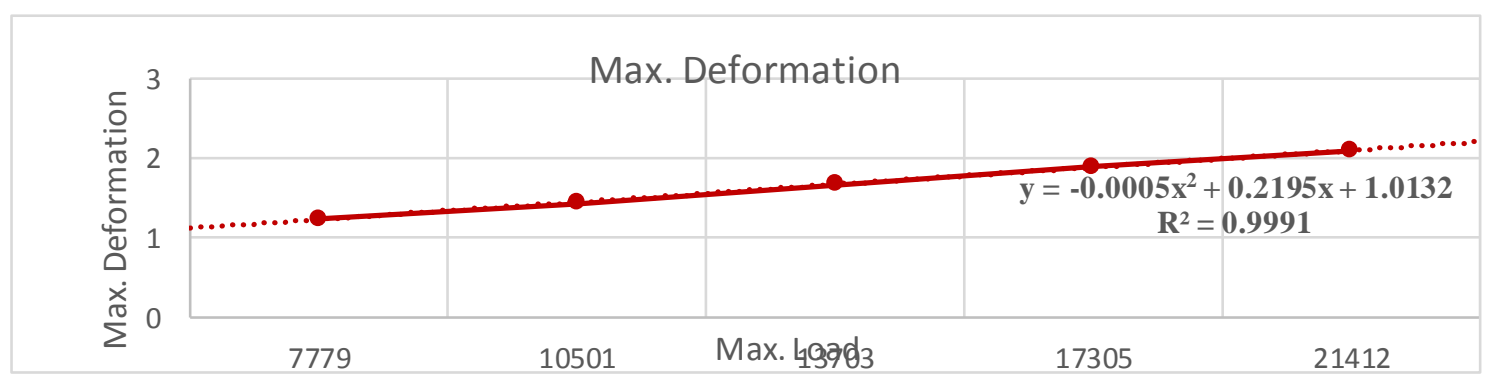


Graph 2 Max. Deformation occurring at various load conditions for tensile te st

\section{Izod Impact Test}

The table below depicts the Impact test results for various specimen ranging from $10 \%$ to $50 \%$ Epoxy by volume. The failure deformation and load at the time of failure in various specimen were compared with the help of line chart. The results concluded that the maximum impact strength is observed in the specimen with $10 \%$ epoxy by volume

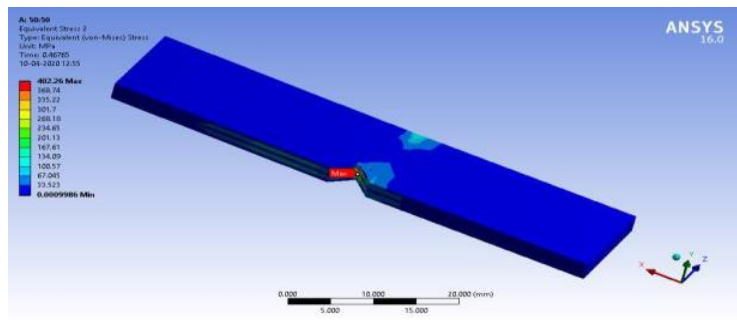

Figure 7. Maximum equivalent stress for Izod impact test

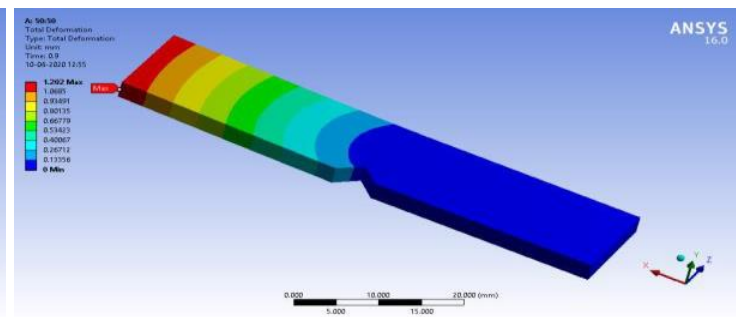

Figure 8. Deformation of Izod

which is just followed by the specimen having $50 \%$ of epoxy. The maximum bearable load of $1201 \mathrm{~N}$ was found in specimen with $10 \%$ epoxy however, maximum deformation of $1.201 \mathrm{~mm}$ was seen in specimen with $50 \%$ epoxy. While, the minimum deformation and bearable load values of 0.846 and $838 \mathrm{~N} \mathrm{~mm}$ were observed in specimen with $30 \%$ and $40 \%$ of epoxy respectively.

Table 3 Results of Izod impact test

\begin{tabular}{|c|c|c|c|}
\hline $\begin{array}{c}\text { Volume \% of } \\
\text { Epoxy }\end{array}$ & $\begin{array}{c}\text { Max. Load } \\
(\mathbf{N})\end{array}$ & $\begin{array}{c}\text { Max. Stress } \\
(\mathbf{M P a})\end{array}$ & $\begin{array}{c}\text { Max. } \\
\text { Deformation } \\
(\mathbf{m m})\end{array}$ \\
\hline 10 & 1201 & 679.88 & 0.975 \\
\hline 20 & 1112 & 611.03 & 0.932 \\
\hline 30 & 859 & 542.06 & 0.846 \\
\hline 40 & 838 & 472.12 & 0.925 \\
\hline 50 & 1105 & 401.94 & 1.201 \\
\hline
\end{tabular}

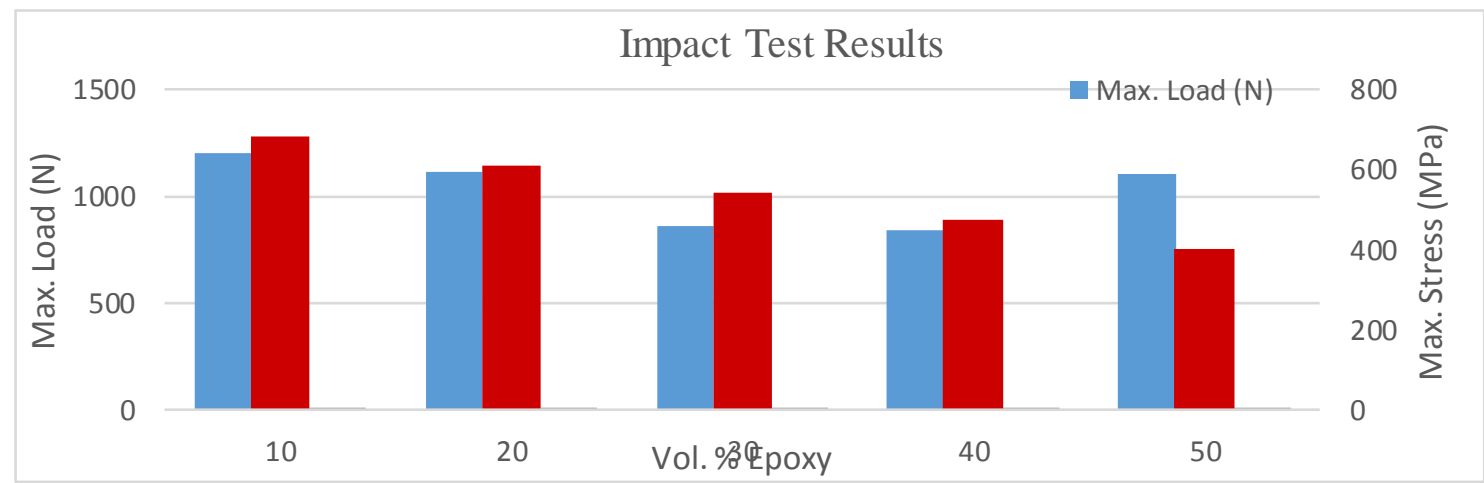


Graph 3. Max. Load and Max. Stress vs \% volume of epoxy for impact test

Graph 4. Max. Deformation occurring at various load conditions for Impact test

\section{Flexural Test}

The table below depicts the Flexural test results for various specimen ranging from $10 \%$ to $50 \%$ Epoxy by volume. Additionally, a line graph was plotted to compare the maximum load just before failure and highest deformation due to tensile loading for various specimens. It was found that the specimen with $10 \%$ epoxy volume displayed the

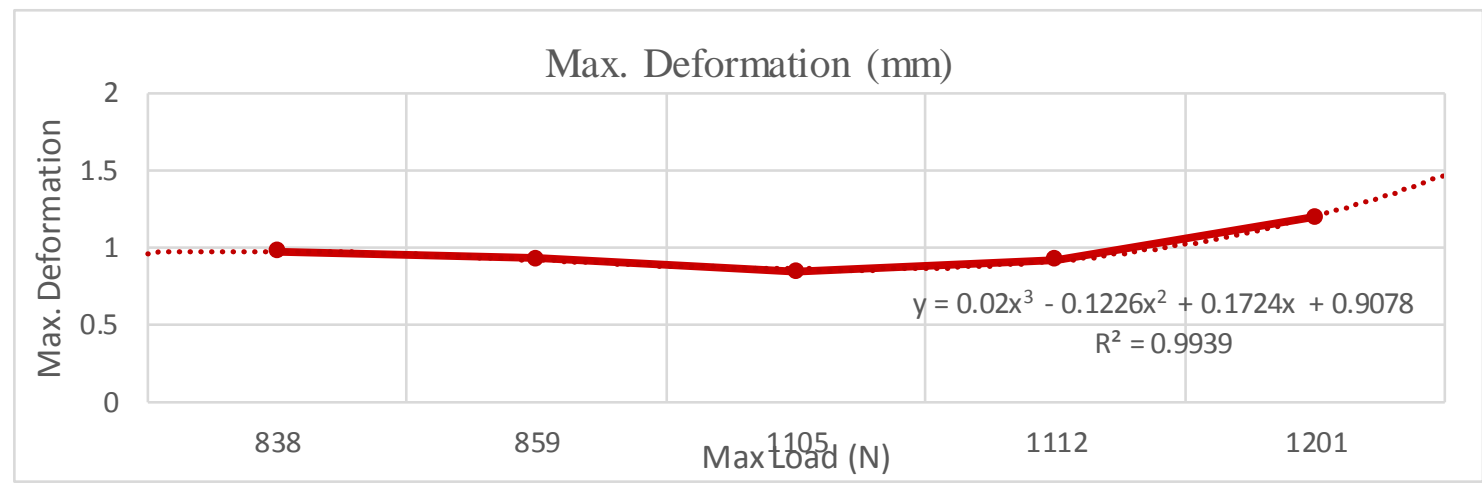

highest Flexural strength and which then steadily decreases as the Vol.\% of Epoxy increases.

The highest deformation of $2.378 \mathrm{~mm}$ and maximum bearable load of $1512 \mathrm{~N}$ was observed in the specimen with $10 \%$ epoxy. Whereas, the specimen with $50 \%$ epoxy gave the lowest deformation of 1.958 and the minimum bearable load value of $518 \mathrm{~N}$.

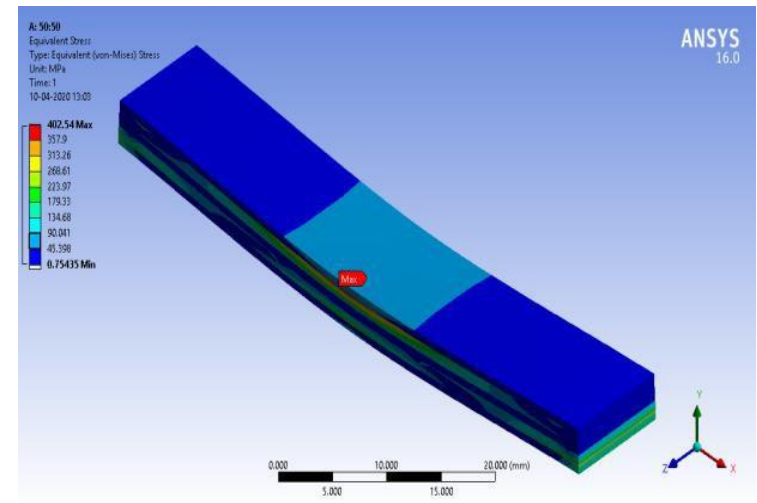

Figure 9 Maximum equivalent stress for Flexural test

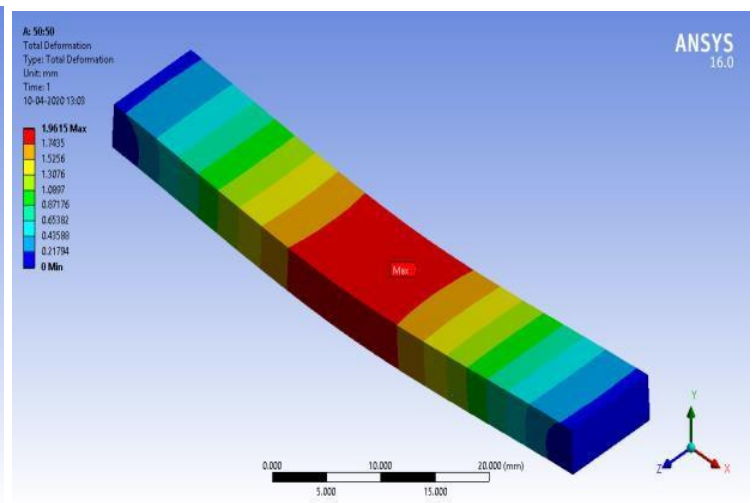

Figure 10. Deformation of Flexural test

Table 4. Results of Flexural test

\begin{tabular}{|c|c|c|c|}
\hline $\begin{array}{c}\text { Volume \% of } \\
\text { Epoxy }\end{array}$ & $\begin{array}{c}\text { Max. Load } \\
\text { (N) }\end{array}$ & $\begin{array}{c}\text { Max. } \\
\text { Stress } \\
\text { (MPa) }\end{array}$ & $\begin{array}{c}\text { Max. } \\
\text { Deformation } \\
(\mathbf{m m})\end{array}$ \\
\hline 10 & 1512 & 681.12 & 2.378 \\
\hline 20 & 1034 & 609.84 & 2.227 \\
\hline 30 & 885 & 540.98 & 2.261 \\
\hline
\end{tabular}




\begin{tabular}{|l|l|l|l|}
\hline 40 & 698 & 472.25 & 2.134 \\
\hline 50 & 518 & 403.15 & 1.958 \\
\hline
\end{tabular}

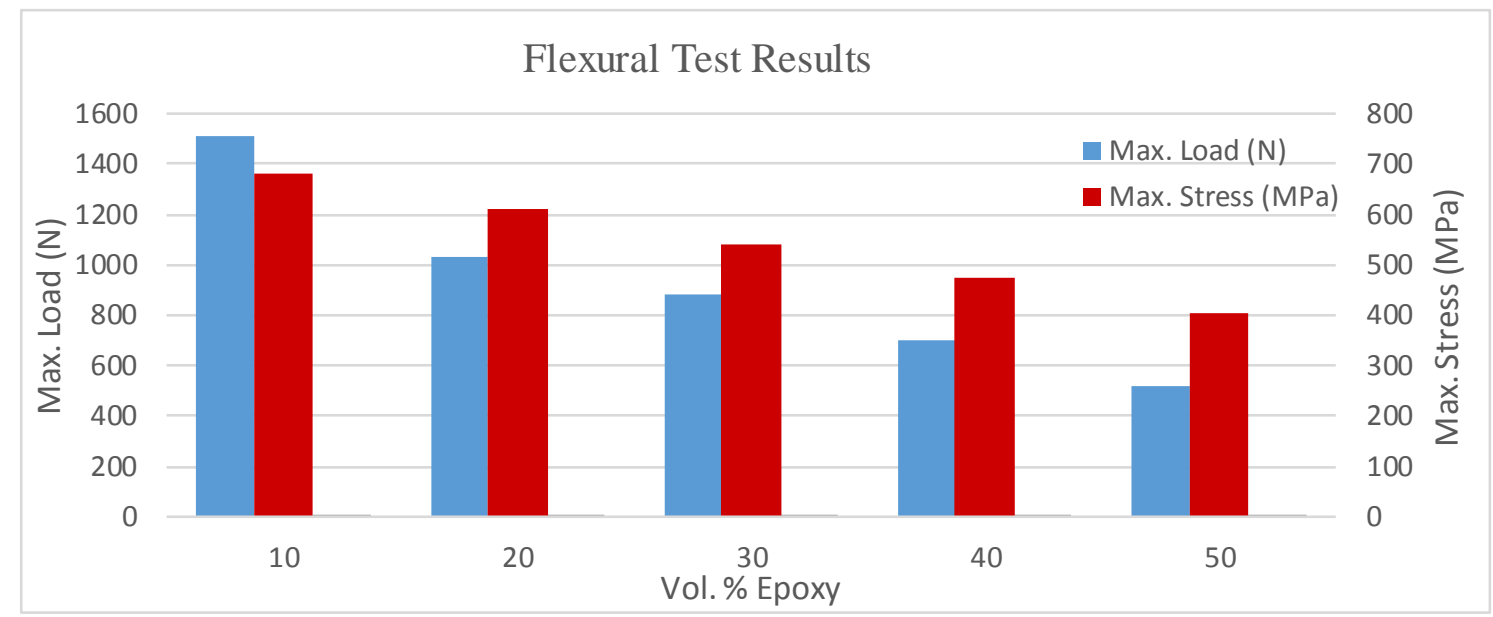

Graph 5 Max. Load and Max. Stress vs \% volume of epoxy for Flexural test

Graph 6 Max. Deformation occurring at various load conditions for Flexural test
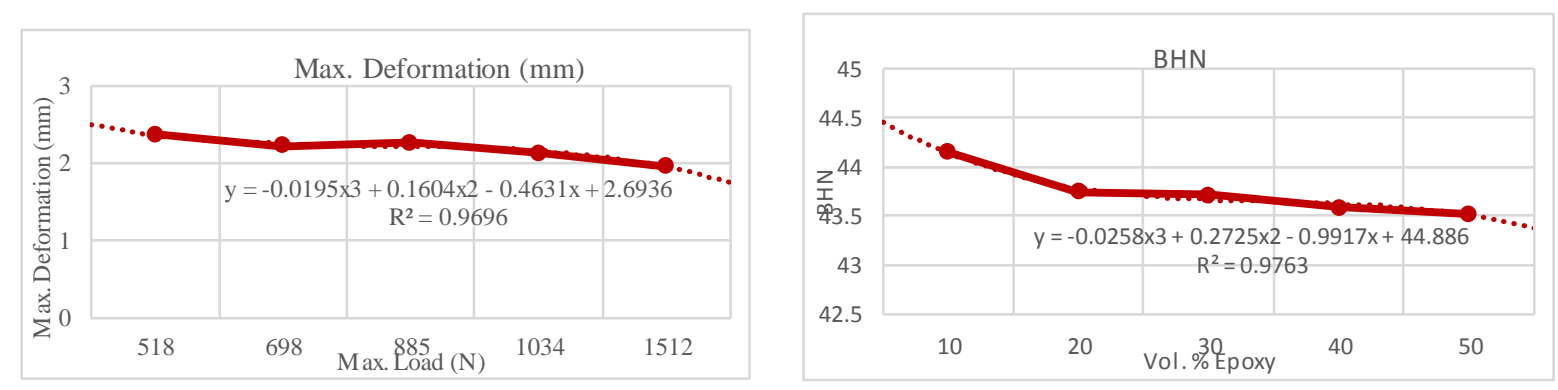

Graph 7. BHN at various vol. \% of epoxy

\section{Hardness Test}

The table below displays the Brinell hardness test results for various specimen ranging from $10 \%$ to $50 \%$ Epoxy by volume. Additionally, a line graph was plotted to compare the BHN for various specimen. The maximum BHN of 44.15 was observed in $10 \%$ epoxy specimen and the minimum BHN of 43.52 was seen in specimen of $50 \%$ epoxy composite. 
Table 5. Results of Flexural test

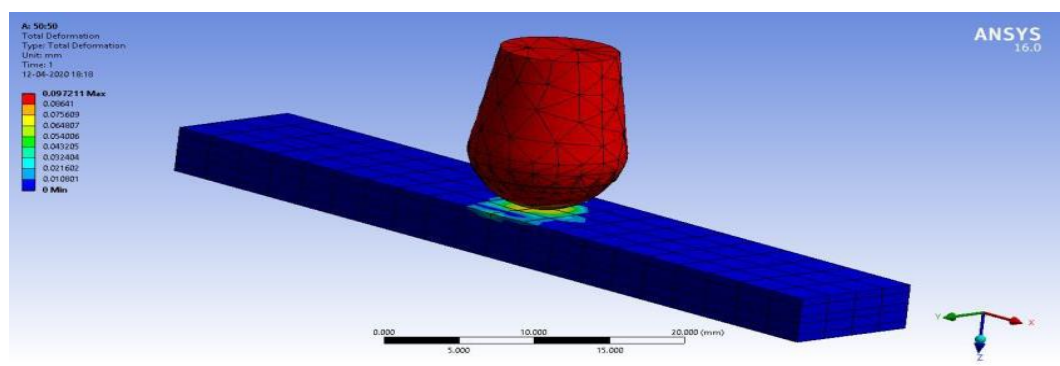

Figure 11 Hardness test

\section{Deflection and Stiffness Test}

The table below depicts the Deflection and stiffness test results for various specimen ranging from $10 \%$ to $50 \%$ Epoxy by volume. The deflection and stiffness at constant load in various specimen were compared with the help of line chart. The results concluded that the maximum deflection is observed in the specimen with $40 \%$ epoxy by volume which is just followed by the specimen having $20 \%$ of epoxy. The maximum stiffness of 215.479

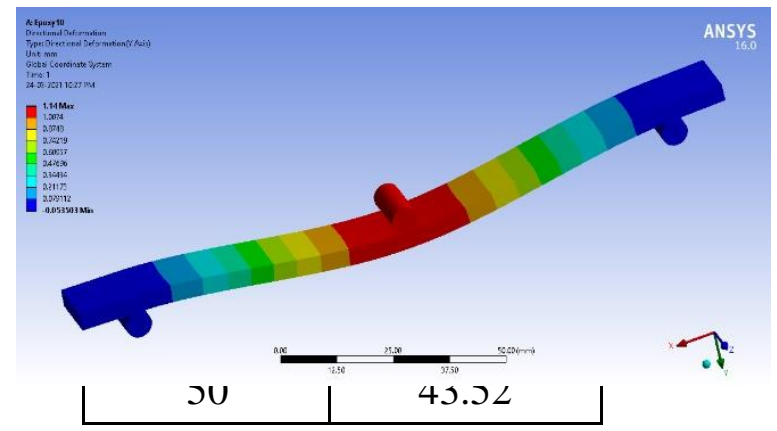

Figure 12 Maximum Deflection under load

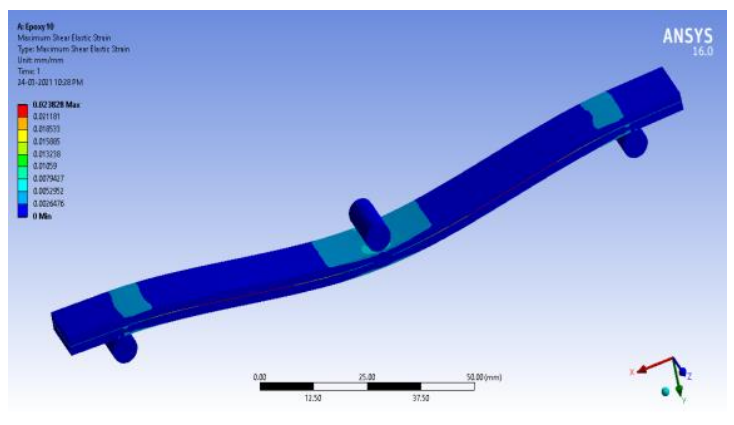

Figure 13 Maximum strain at the
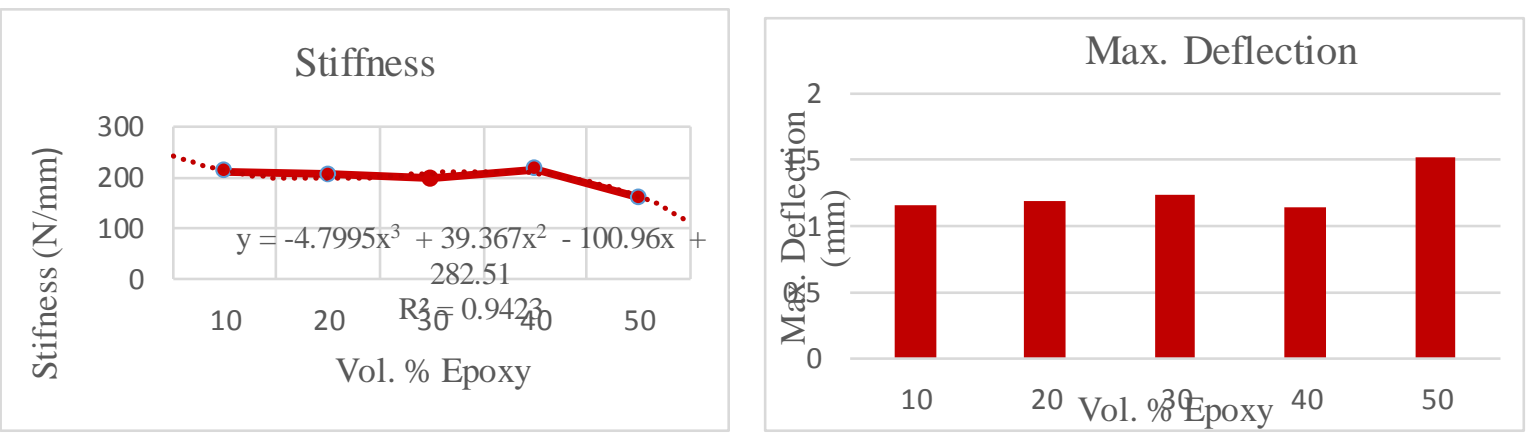

outer surface

Graph 8. Max. Deflection vs \% volume of epoxy for Deflection test. Graph 9. Stiffness of Various specimens under constant load condition

\section{CONCLUSION}

As per the current study, the failure stresses for banana-epoxy composite of compositions were estimated and the values of which were used to calculate the maximum bearable 
load of the ASTM standard size specimen of tensile, flexural and Izod impact tests. It was found in the literature survey that the finite element model is very reliable for studying the mechanical behavior of fibre composite and hence it was used for studying the characteristics of fibre composite. It is observed that the composite with least volume percent of epoxy has better mechanical strength and can bear higher deformation under higher load in tensile and flexural tests. However, the results of impact test show a decrease in maximum bearable load with the increase in \% volume of epoxy, then the load value starts increasing at some point between 30-40\% and the trend is further continued. Similar trend was seen for maximum deformation under impact load. Also, with increase in \% volume of epoxy, the hardness of the specimen decreases. The maximum bearable tensile load was observed in specimen with $10 \%$ volume of epoxy and the value came out to be $21412 \mathrm{~N}$ with maximum deformation of $2.092 \mathrm{~mm}$. The maximum flexural load of $1512 \mathrm{~N}$ with maximum deformation of $2.378 \mathrm{~mm}$ was observed in the $10 \%$ specimen and so was maximum impact load which comes out to be $1201 \mathrm{~N}$, however maximum deformation in impact test of $1.201 \mathrm{~mm}$ was observed in 50 $\%$ specimen. The maximum BHN of 44.15 was observed in the $10 \%$ composite while the minimum $\mathrm{BHN}$ of 43.52 was observed in the $50 \%$ composite. The minimum deflection of $1.137 \mathrm{~mm}$ and maximum stiffness of $215.479 \mathrm{~N} / \mathrm{mm}$ was observed in specimen with $40 \%$ epoxy. It was observed that as the volume $\%$ of epoxy increases, stiffness decreases, and deflection increases. However, it was not true for the specimen with $40 \%$ epoxy by volume. Moreover, the lowest stiffness of $160.761 \mathrm{~N} / \mathrm{mm}$ was found in specimens with 50\% vol. of epoxy along with the highest deflection at $1.524 \mathrm{~mm}$.

\section{REFERENCES}

M. Ramesh, R. Logesh, M. Manikandan, N. S. Kumar, and D. V. Pratap, 'Mechanical and water intake properties of banana-carbon hybrid fiber reinforced polymer composites', Mater. Res., vol. 20, no. 2, pp. 365-376, 2017, doi: 10.1590/19805373-MR-2016-0760.

C.W., "'V. D. M.", Notes Queries, vol. 151, no. SEP18, p. 208, 1926, doi: 10.1093/nq/CLI.sep18.208-b.

V. Prasad, A. Joy, G. Venkatachalam, S. Narayanan, and S. Rajakumar, 'Finite element analysis of jute and banana fibre reinforced hybrid polymer matrix composite and optimization of design parameters using ANOVA technique', Procedia Eng., vol. 97, pp. 1116-1125, 2014, doi: 10.1016/j.proeng.2014.12.390. 
R. T. Suryawanshi, G. Venkatachalam, and S. V. Vimalanand, 'Determination of stress intensity factor of banana fibre reinforced hybrid polymer matrix composite using finite element method', Period. Polytech. Mech. Eng., vol. 60, no. 3, pp. 180184, 2016, doi: 10.3311/PPme.8991.

L. José da Silva, T. Hallak Panzera, A. Luis Christoforo, L. Miguel Pereira Dur, and F. Antonio Rocco Lahr, 'Numerical and Experimental Analyses of Biocomposites Reinforced with Natural Fibres', Int. J. Mater. Eng., vol. 2, no. 4, pp. 43-49, 2012, doi: 10.5923/j.ijme.20120204.03.

Ps. Shankar, D. Reddy, Vc. sekhar, and Vc. Sekhar, 'Mechanical Performance and Analysis of Banana Fiber Reinforced Epoxy Composites', Int. J. Recent Trends Mech. Eng., vol. 1, no. 4, pp. 440-444, 2013, [Online]. Available: http://iret.co.in/Docs/IJRTME/Volume 4/Issue1/1. Mechanical Performance and Analysis of Banana Fiber Reinforced Epoxy Composites.pdf.

M. Rajesh, T. Srinag, P. P. Prasanthi, and K. Venkataraovenkatarao, 'Finite Element Analysis of Coir / Banana Fiber Reinforced Composite material', Int. J. Adv. Res. Mech. Eng. Technol., vol. 2, no. 4, pp. 29-33, 2016.

U. S. Gupta, M. Dhamarikar, A. Dharkar, S. Chaturvedi, S. Tiwari, and R. Namde o, 'Surface modification of banana fiber: A review', Mater. Today Proc., Aug. 2020, doi: 10.1016/j.matpr.2020.07.217.

K. Balasubramanian, N. Rajeswari, and K. Vaidheeswaran, 'Analysis of mechanical properties of natural fibre composites by experimental with FEA', Mater. Today Proc., vol. 28, no. xxxx, pp. 1149-1153, 2019, doi: 10.1016/j.matpr.2020.01.098.

M. Engineering, 'Coir-Banana', vol. 4, no. June, pp. 518-531, 2013, [Online]. Available: http://dx.doi.org/10.15282/jmes.4.2013.16.0049\%0D.

S. Dixit and S. S. Padhee, 'Finite element analysis of fiber reinforced hybrid composites', Mater. Today Proc., vol. 18, pp. 3340-3347, 2019, doi: 10.1016/j.matpr.2019.07.255.

M. D. Monzón et al., 'Experimental analysis and simulation of novel technical textile reinforced composite of banana fibre', Materials (Basel)., vol. 12, no. 7, 2019, doi: $10.3390 / \operatorname{ma1} 2071134$.

M. Ramesh and P. Sudharsan, 'Experimental Investigation of Mechanical and 
Morphological Properties of Flax-Glass Fiber Reinforced Hybrid Composite using Finite Element Analysis', Silicon, vol. 10, no. 3, pp. 747-757, 2018, doi: 10.1007/s12633-016-9526-5.

V. Prasad, G. Venkatachalam, A. Rathi, and S. Rajakumar, 'Finite element analysis of jute fibre made hybrid polymer matrix composite', Appl. Mech. Mater., vol. 592-594, pp. 363-367, 2014, doi: 10.4028/www.scientific.net/AMM.592-594.363.

M. Ramesh and S. Nijanthan, 'Mechanical property analysis of kenaf-glass fibre reinforced polymer composites using finite element analysis', Bull. Mater. Sci., vol. 39, no. 1, pp. 147-157, 2016, doi: 10.1007/s12034-015-1129-z.

A. G. Adeniyi, S. A. Adeoye, D. V. Onifade, and J. O. Ighalo, 'Multi-scale finite element analysis of effective elastic property of sisal fiber-reinforced polystyrene composites', Mech. Adv. Mater. Struct., vol. 0, no. 0, pp. 1-9, 2019, doi: 10.1080/15376494.2019.1660016.

S. B. R. Devireddy and S. Biswas, 'Effect of Fiber Geometry and Representative Volume Element on Elastic and Thermal Properties of Unidirectional FiberReinforced Composites', J. Compos., vol. 2014, pp. 1-12, 2014, doi: $10.1155 / 2014 / 629175$.

M. Idicula, S. K. Malhotra, K. Joseph, and S. Thomas, 'Dynamic mechanical analysis of randomly oriented intimately mixed short banana/sisal hybrid fibre reinforced polyester composites', Compos. Sci. Technol., vol. 65, no. 7-8, pp. 1077-1087, 2005, doi: 10.1016/j.compscitech.2004.10.023.

K. N. Indira, J. Parameswaranpillai, and S. Thomas, 'Mechanical Properties and Failure Topography of Banana Fiber PF Macrocomposites Fabricated by RTM and CM Techniques', ISRN Polym. Sci., vol. 2013, pp. 1-8, 2013, doi: 10.1155/2013/936048. 